\title{
Viremia-associated ana-aki-byo, a new viral disease in color carp Cyprinus carpio in Japan
}

\author{
Teruo Miyazaki*, Hiroyuki Okamoto, Tetsusi Kageyama, Tatsuya Kobayashi
}

Faculty of Bioresources, Mie University, 1515 Kamihama, Tsu, Mie 514-8507, Japan

\begin{abstract}
A new virus disease that displays dermal ulceration and high mortality has been occurring since 1996 in color carp Cyprinus carpio reared in warm water in Japan. In histological examinations, initial erosive lesions displayed necrosis, hemorrhage and fibrin deposition in the dermal loose connective tissue and were accompanied by the partial destruction of the epidermis. Developed ulcerative lesions involved the lateral musculature with bacterial invasions. In visceral organs, necrotic cells were observed in the hematopoietic tissue, the spleen and the intestinal tissues as well as in cardiac muscle fibers which showed no signs of bacterial invasion. Electron microscopy revealed corona-like virus particles in these necrotic cells. The necrotic cells of the hematopoietic tissue and the spleen were accompanied by the formation of tubular structures and crystalline inclusions. The putative virus was isolated and cultured in epithelioma papillosum cyprini (EPC) cells. Carp experimentally inoculated with the cultured virus showed virus transmission, and the same pathological signs of the disease and mortalities as in natural infections.
\end{abstract}

KEY WORDS: Corona-like virus - Carp Dermal ulceration - Hematopoietic necrosis - Splenic necrosis Myocardial necrosis - Viremia $\cdot$ Tubular structure $\cdot$ Crystalline inclusion

\section{INTRODUCTION}

In Japan, some dermal ulcer diseases have been occurring in cyprinid fishes such as color carp Cyprinus carpio, goldfish and crucian carp Carassius auratus since 1971 . These diseases were caused by or associated with Cytophaga columnaris (Flexibacter columnaris) (Miyazaki \& Egusa 1973), Aeromonas hydrophila (Takahashi et al. 1975a,b,c, Saito et al. 1975) and a coldwater gliding bacterium (Miyazaki et al. 1976a,b,c), and, as a group, have been called 'ana-aki-byo', which means ulcer-forming disease in Japanese. At the same time, a carp ulcer disease called carp erythro-dermatitis that was associated with $A$. salmonicida, which might be an atypical $A$. salmonicida, occurred in European countries (Bootsma et al. 1977). In 1980, an atypical $A$. salmonicida was isolated from ulcerative dermal lesions of diseased goldfish and was confirmed as a primary pathogen based on the results of infectivity experiments (Eriot \& Shotts 1980a,b). This bacterial disease

•E-mail.miyazaki@bio.mie-u.ac.jp was named ulcerative furunculosis in order to differentiate it from ana-aki-byo. Then, in Japan, A. hydrophila was recognized as a secondary invader in ana-aki-byo that broke out in cold water. However, there was still some doubt as to whether an atypical $A$. salmonicida was the primary cause of disease because the initial sign of the dermal lesion in the natural outbreak was different to that which was observed in the experimental infection. The above-mentioned ana-aki-byo has not been a major disease since 1975. In recent years, however, a new ana-aki-byo occurred again in color carp all over Japan. This new disease was different from the previous ana-aki-byo in that outbreaks occurred in warm water, the disease caused high mortality, chemotherapeutic treatments were not effective, and there was no dominant bacterium in the ulcerative dermal lesions. The most marked difference was the occurrence of necrotic lesions in visceral organs. Such lesions were not observed in the previous ana-aki-byo (Miyazaki \& Egusa 1973, Miyazaki et al. 1976c). The present study was conducted to investigate the cause of this new ana-aki-byo. Here we present the results of 
histopathological and electron microscopic studies, and report the isolation and culture of the causative virus. The results of infectivity experiments are also reported.

\section{MATERIALS AND METHODS}

Diseased fish in natural outbreak. A total of 30 diseased carp with dermal ulcerations were collected from farming ponds in Hiroshima, Niigata and Mie Prefectures and a game-fishing pond in Osaka Prefecture, Japan, in 1997-1998.

Histopathological and electron microscopic examinations. The sampled fish were dissected after external and internal examination. Pieces of the dermal lesions and visceral organs were fixed in $10 \%$ phosphate-buffered formalin for histological studies. The fixed tissues were prepared according to standard techniques and stained with hematoxylin \& eosin (H\&E), Azan, Giemsa, Berlin blue and Periodic Acid Schiff (PAS) reaction. Pieces of the remaining dermal lesion and kidney were fixed in $70 \%$ Karnovsky solution, postfixed in $1 \% \mathrm{OsO}_{4}$ and processed for electron microscopy (EM) according to standard techniques

Cell lines, virus culture and virology tests. Because histopathological observations showed signs of virus infection, 5 cell lines as EK-1 (eel kidney), FHM (fathead minnow), CHSE-214 (chinook salmon embryo), RTG-2 (rainbow trout gonad) and EPC (epithelioma papillosum cyprini) were inoculated with filtrates of fish tissues in order to select a sensitive cell line. Because only the EPC cell line was sensitive to the putative virus, this cell line was used for virus isolation and culture. For virus isolation, pieces of the dermal lesion, kidney, spleen and heart were excised from diseased fish and each piece was homogenized in 10 volumes of the culture medium using a glass homogenizer. The homogenate was filtered through a $450 \mathrm{~nm}$ filter, and the EPC cells were inoculated with $0.5 \mathrm{ml}$ of the filtrate in $5 \mathrm{ml}$ of culture medium in a $25 \mathrm{~cm}^{3}$ flask. Inoculated EPC cells were cultured with Eagle's MEM (Nissui) with the addition of $2 \%$ fetal bovine serum (FBS), which made a 40 d cultivation possible because highly effective FBS (Biosciens PTY) was selected for the EPC cell culture. Inoculated cells were incubated at $25^{\circ} \mathrm{C}$ until a cytopathic effect (CPE) appeared. Titration, 10 -fold dilution for cloning, ether sensitivity and 5-iodo-2-deoxyuridine (IUdR) resistance were determined in micro-titer plates according to standard techniques. In this study, the first and second passages of virus isolates were used for virological tests and infectivity experiments for the reasons mentioned in the 'Results' EM was also performed in infected EPC cells in order to determine the virus isolation and morphology of the virus particles.
Infectivity experiments. Experimental infections were attempted by either an intracutaneous or intraperitoneal injection of cultured virus using healthy carp (10 to $20 \mathrm{~g}$ body weight) which were obtained from a farming pond that had not experienced an epizootic of the new ana-aki-byo. All experimental fish were treated with $50 \mathrm{ppm}$ formalin solution in order to remove external parasites before the experiments. All inocula containing the cultured virus was injected at $1 \mathrm{ml}$ per $100 \mathrm{~g}$ body weight. In 2 groups that were inoculated intracutaneously, 1 group (10 fish; $10^{4.1} \mathrm{TCID}_{50}$ $\mathrm{ml}^{-1}$ ) was held in aquaria containing $0.05 \%$ oxytetracycline which was renewed once a week during the experiment in order to prevent bacterial invasions into dermal lesions. The other group ( 8 fish; $10^{7.0}$ TCID $_{50}$ $\mathrm{ml}^{-1}$ ) did not experience such oxytetracycline treatment and thus their dermal lesions were exposed to invasions of water-borne bacteria. Some fish in which dermal lesions occurred were removed for histopathological examinations during the experiments. In addition, 4 groups (5 to 8 fish) were challenged by an intraperitoneal inoculation at $10^{5.0-7.0} \mathrm{TCID}_{50} \mathrm{ml}^{-1}$ of the cultured virus and the mortality was observed. Control groups (each 10 fish), 1 group for each method of injection, were injected with culture medium. Injected fish were held in aquaria with aeration at $25^{\circ} \mathrm{C}$. Dead and moribund fish were removed from the aquaria and their tissues were prepared for histopathological and EM examinations. Virus was also reisolated from the dermal lesion, kidney and heart. Moreover, at the end of experiment, all surviving fish and all control fish were also removed from the aquaria and their tissues were prepared for histopathological examination and virus isolation as in diseased fish.

\section{RESULTS}

\section{External and histopathological findings and electron microscopy in natural outbreak}

Diseased carps displayed erosive and ulcerative lesions along with intracutaneous hemorrhage in the body surface of the trunk, fins and the snout. In the ulcerative lesions on the body, scales were separated and either the dermis or the lateral musculature was involved (Fig. 1A). Some diseased fish showed mortality even though they had only slight dermal lesions. In visceral organs, the heart was slightly swollen and the kidney was swollen and discolored. Using brain heart infusion agar plates, several kinds of bacterial colonies were obtained from ulcerative lesions. However, because there was no dominant type of colony on the plates, further studies on the bacteria were not conducted. 

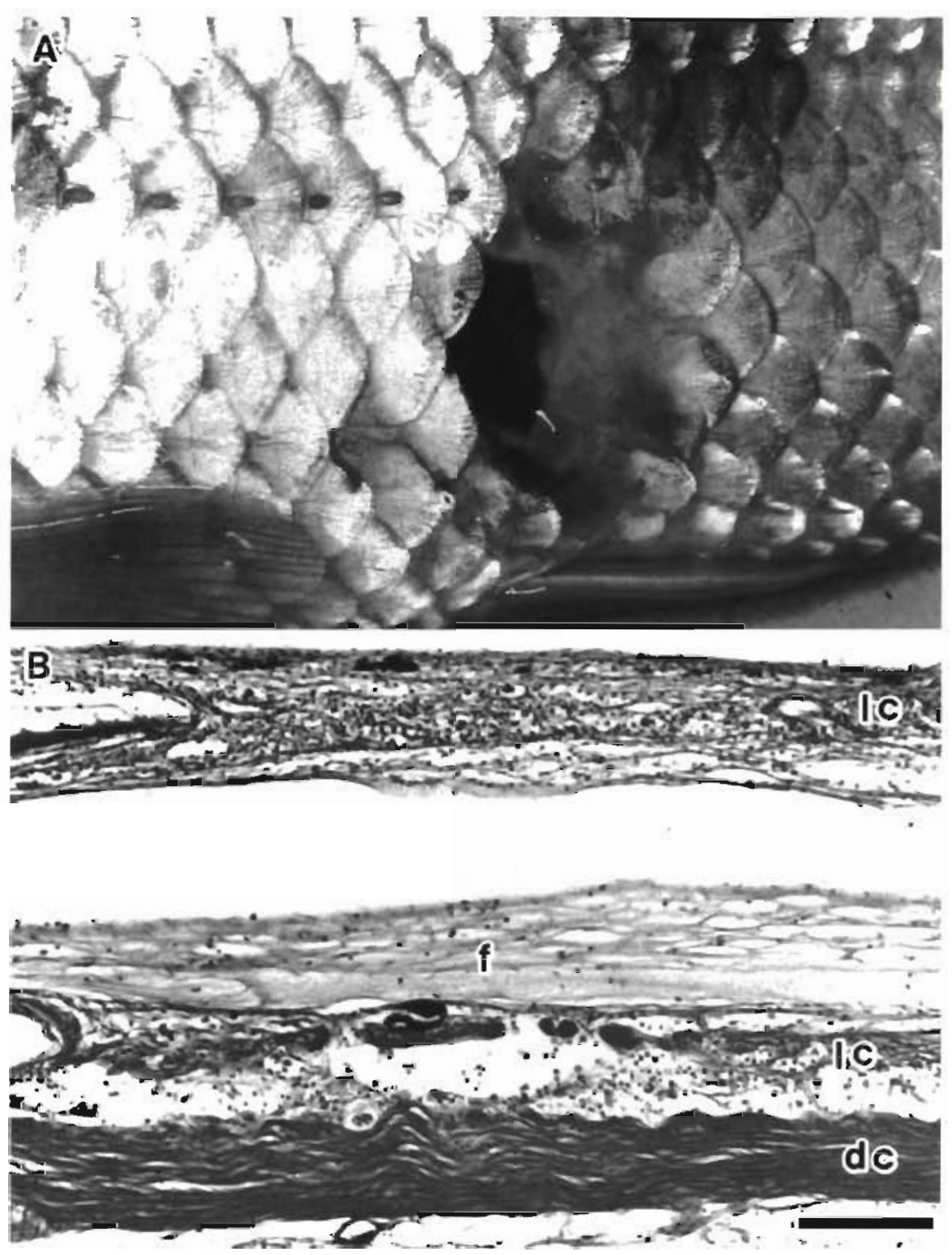

Fig. 1 Cyprinus carpio. (A) External view of a naturally diseased fish which has an ulcerative lesion in the abdomen. (B) An ulcerative lesion, the epidermis and scales are separated. The underlying, dermal loose connective tissue (Ic) shows necrosis, hemorrhage, fibrin deposition (f) and infiltration of inflammatory cells The dermal dense connective tissue $(\mathrm{dc})$ is necrotic. H\&E. Scale bar $=100 \mu \mathrm{m}$

rhage and inflammatory cellular infiltration. In severe cases, ulceration involved the lateral musculature, and the necrotized tissue showed extensive bacterial invasion. In contrast, in healing lesions, regenerating epidermis extended onto either the deposited fibrin layer or the granulation tissue. The granulation tissue grew in the necrotized dermis through the underlying adipose tissue to the superficial layer of the lateral musculature. In these tissues, bacterial invasion was not observed. These signs of healing resembled those described by Miyazaki et al. (1976b).

In the kidney, there were extensively necrotized cells showing karyorrhexis and karyopyknosis, some of which also showed intracytoplasmic vacuolization, in the hematopoietic tissue (Fig. 2A). As necrotized cells were destroyed, they were replaced by empty spaces within the tissue. However, the nephrons were usually spared necrosis. The heart extensively displayed necrosis of the cardiac muscle fibers in the ventricle (Fig. 2B) as well as the auricle. Necrotized muscle fibers usually showed nuclear degeneration and either vacuolization or coagulation of fibers. The spleen displayed many necrotized cells and macrophages phagocytizing hemosiderin and erythrocytes in the sheathed tissue and pulps (Fig. 2C). In some fish, the intestine contained large numbers of necrotized cells in the epithelium and tunica propria (Fig. 2D). The brain showed a small number of necrotized cells within the granular

Histological examinations of erosive lesions showed that the dermal loose connective tissue was necrotized, and was accompanied by hemorrhage, fibrin deposition and inflammatory cellular infiltration. The overlying epidermis was thin and partially separated. No bacterium was observed in these necrotic tissues. The ulcerative lesions were either developing due to bacterial invasion or in a healing stage. In the former case, the skin was extensively necrotized and destroyed, showing signs of bacterial invasion. The necrotic dermis was followed by hemorrhage, fibrin deposition and inflammatory cellular infiltration (Fig. 1B). The underlying lateral musculature contained some necrotized and vacuolized muscle fibers, and displayed hemor- layers. The liver had atrophic hepatocytes, some of which contained slight amounts of hemosiderin. These pathological signs were observed in fish that had all stages of dermal lesions.

EM of necrotic cells in the hematopoietic tissue and the spleen revealed virus particles within the vacuolized cytoplasm. In the hematopoietic tissue, reticulocyte, reticulo-endothelial cells lining sinusoid, and hematopoietic cells were infected. In the spleen, reticulocyte in pulps and splenocyte in the sheathed tissues were mainly infected. The putative virus particles had a round shape, an obviously spiked surface and diameters varying from 100 to $180 \mathrm{~nm}$ (Fig. 3A,B). The shape of the surface spikes was that of a long 


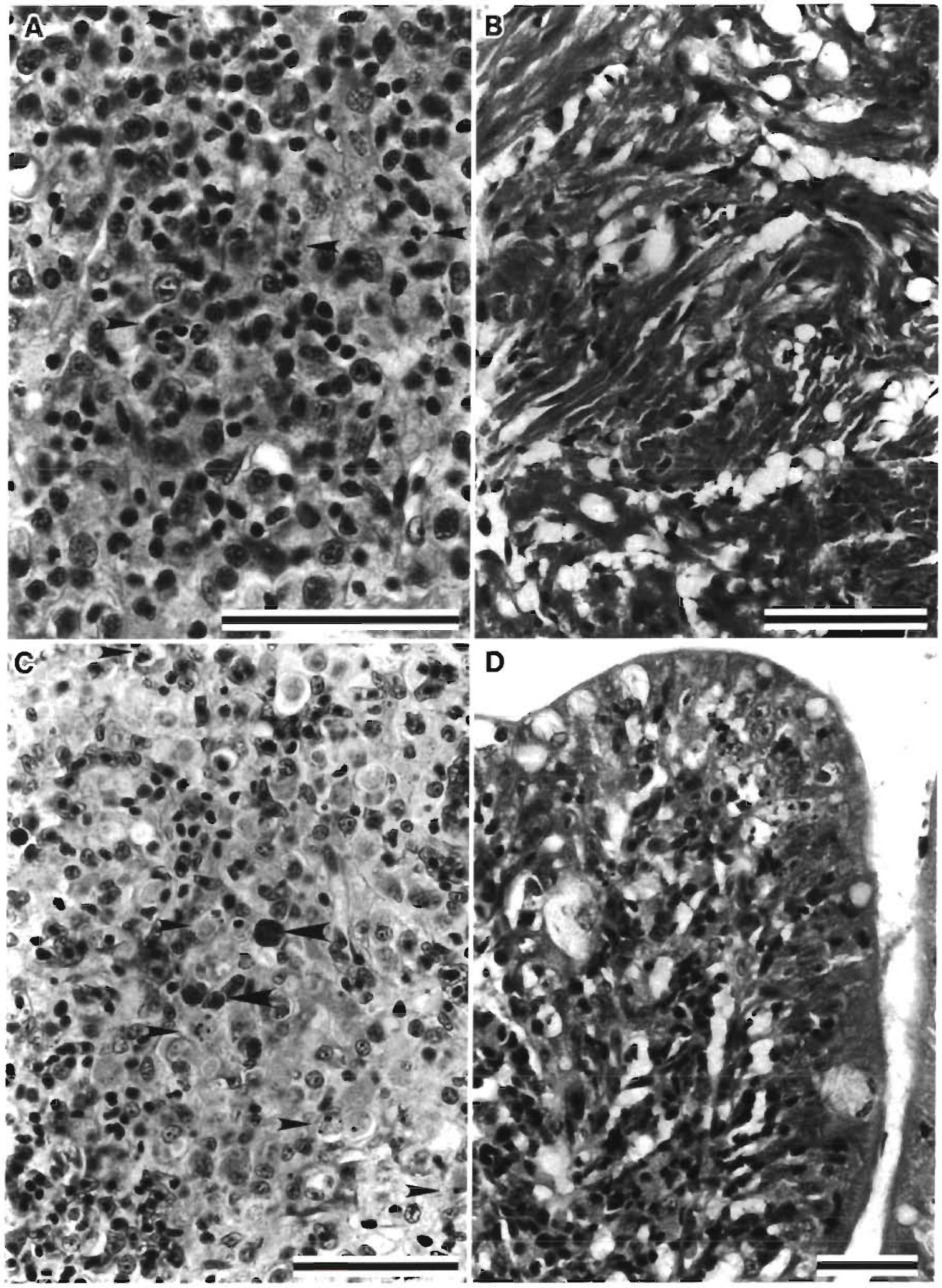

Fig. 2. Histopathological signs of visceral organs in the natural outbreak. H\&E. Scale bars $=50 \mu m$. (A) Hematopoietic tissue displays necrotized cells with karyorrhexis (arrowheads). (B) Ventricle shows coagulation necrosis and vacuolar degeneration of muscle fibers. (C) Spleen exhibits necrotized cells with karyorrhexis (arrowheads) and hemosiderin bearing cells (big arrowheads) in the sheathed tissue. (D) Intestinal villus exhibits necrotized cells in the tunica propria and the epithelium 


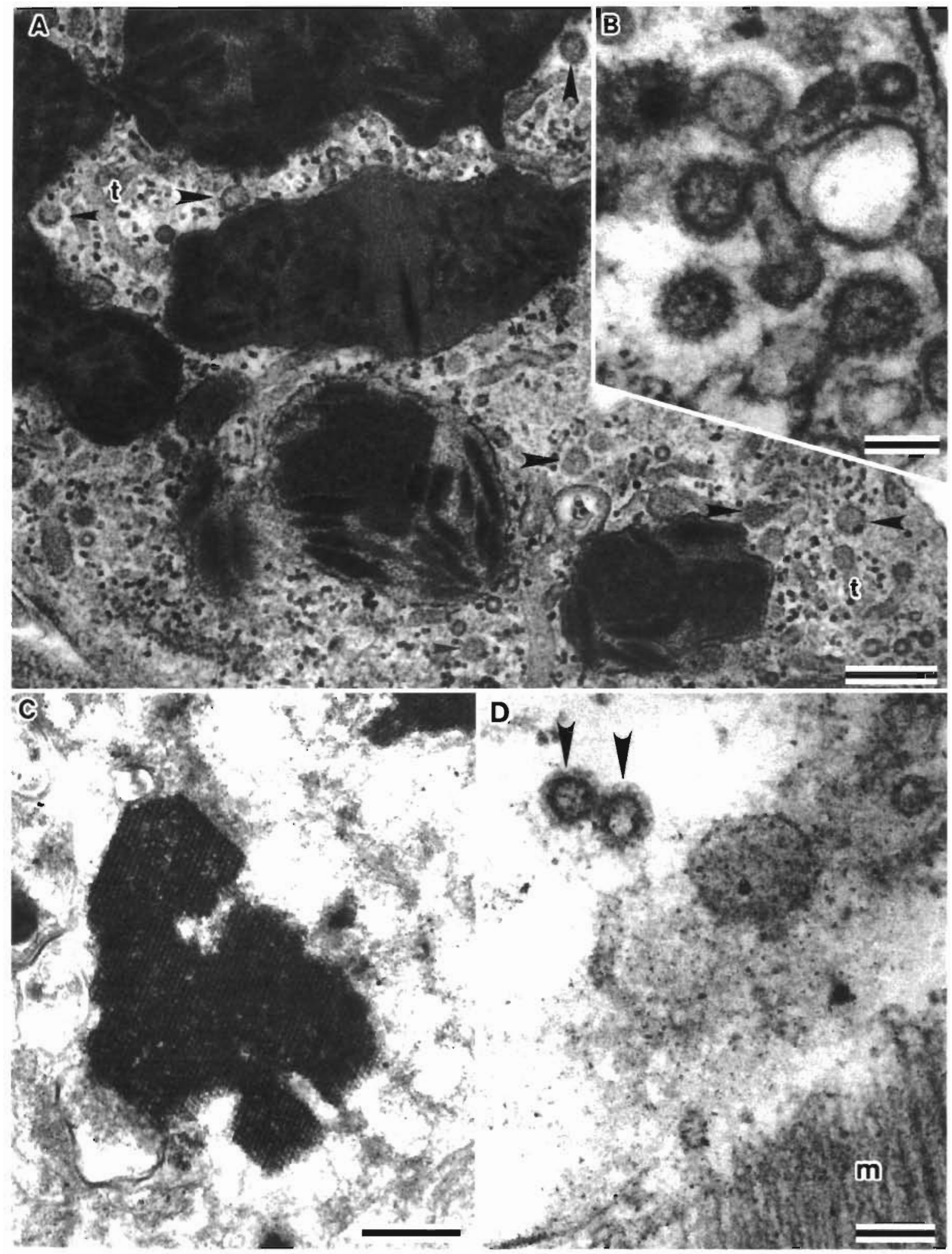

Fig. 3. Electron micrographs of infected cells in the natural outbreak. (A-C) Infected hematopoietic cells. (A) Infected cell displays virions (arrowheads), tubular structures (t) and electron-dense materials containing many crystalline inclusions in the vacuolized cytoplasm. Scale bar $=400 \mathrm{~nm}$. (B) Enlarged photograph of virions. Virions have the distinct spikes on the envelope. Scale bar $=100 \mathrm{~nm}$. (C) Detail of crystalline inclusions. The crystal consists of strongly electron-dense lines $33 \mathrm{~nm}$ in diameter arrayed to form a lattice. The crystal is apparent after electron-dense materials have been destroyed. Scale bar $=500 \mathrm{~nm}$. (D) Infected, cardiac muscle fiber in the ventricle contains virions (arrowheads) in the vacuolized myoplasm. m: myofibril. Scale bar $=150 \mathrm{~nm}$ 
rod or club, which was different from the shape of the ribosomes and suggested that the particles were not transporting vesicles derived from granular endoplasmic reticula. In these infected cells, mitochondria, reticula and Golgi apparatus had been destroyed and had disappeared. Moreover, these infected cells also displayed the formation of tubular structures and electron-dense materials containing crystalline inclusions (Reinke's inclusion; Ghadially 1982) in the cytoplasm. Tubular structures had diameters of 60 to $70 \mathrm{~nm}$ and were of various lengths. Crystalline inclusions usually formed within amorphous, electron-dense materials which varied in size and shape, and were different to the lipofuscin pigment (Ghadially 1982) because of the absence of lipid within them. The crystals tended to occur initially as small masses with a high electron density and to be subsequently distinct in structure. The crystals displayed a polygon or parallelogram morphology in section and consisted of either 3-dimensional arrays of strongly electron-dense lines $33 \mathrm{~nm}$ in diameter, dots that formed parallel lines or a prismatic or hexagonal lattice (Fig. 3C). The crystals remained after electron-dense materials had been destroyed following the destruction of infected cells. In contrast, unaffected cells did not show virus-like particles or the formation of tubular and crystal structures that were found in infected cells. However, necrotized cardiac muscle fibers also contained the same virus particles in the myoplasm that was vacuolized, which did not contain glycogen granules and showed degenerated mitochondria and reticula, while myofibrils were fragmented or coagulated (Fig. 3D). The infected fibrocytes of the ulcerated dermal loose connective tissue also displayed viruslike particles and electron-dense materials, while in these cells crystalline inclusions were not distinctive.

\section{Virus isolation and culture}

Inoculated EPC cells experienced a single long-term incubation and displayed CPE as karyopyknosis and intracytoplasmic vacuolization after about $20 \mathrm{~d}$ (Fig. 4A) and subsequent separation and a lytic event involving the affected cells by $30 \mathrm{~d}$. The non inoculated cells in the control never showed similar signs after $30 \mathrm{~d}$. The virus isolates allowed the third passage and, therefore, the putative virus isolation was determined, while more than a fourth serial cultivation of the virus was difficult. For the above reason, the primary and secondary passage of virus isolates were used for virological tests and infectivity examinations. In the natural outbreak and infectivity experiments, a putative virus was isolated from the kidney, spleen and heart as well as from dermal lesions, while in some diseased fish, viral isolation was unsuccessful because the ulcerative lesion had been invaded by many bacteria.

The putative virus was resistant to IUdR and sensitive to ether, which indicated it was an RNA virus with an envelope. EM of infected cells revealed the same viruslike particles in the vacuolized cytoplasm (Fig. 4B).
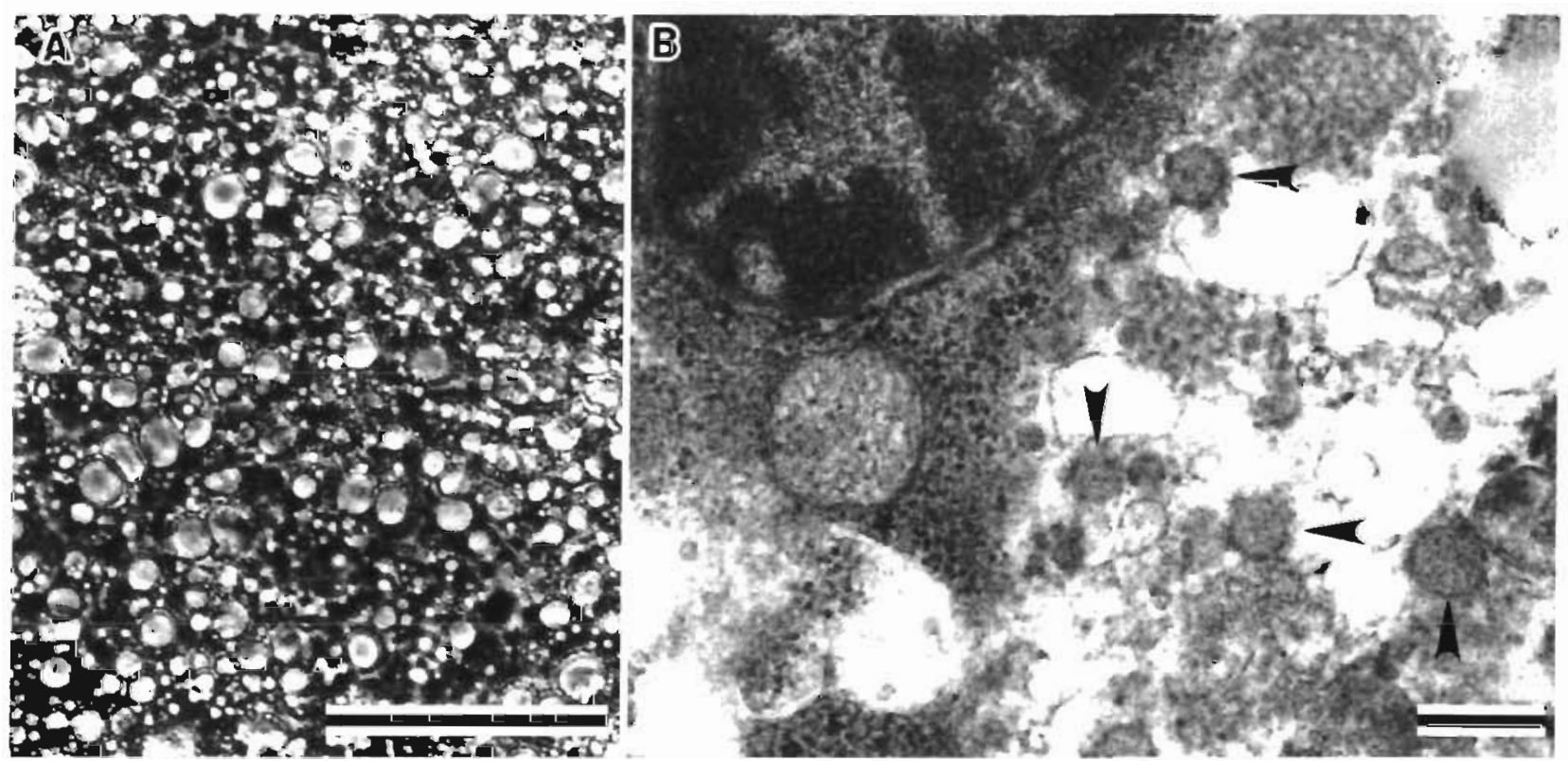

Fig. 4. (A) Cytopathic effect of the infected EPC cells. They show vacuolization and karyopyknosis. Scale bar $=100 \mu \mathrm{m}$. (B) Electron micrograph of an infected EPC cell. Virions (arrowheads) appear in the vacuolized cytoplasm. Scale bar $=350 \mathrm{~nm}$ 


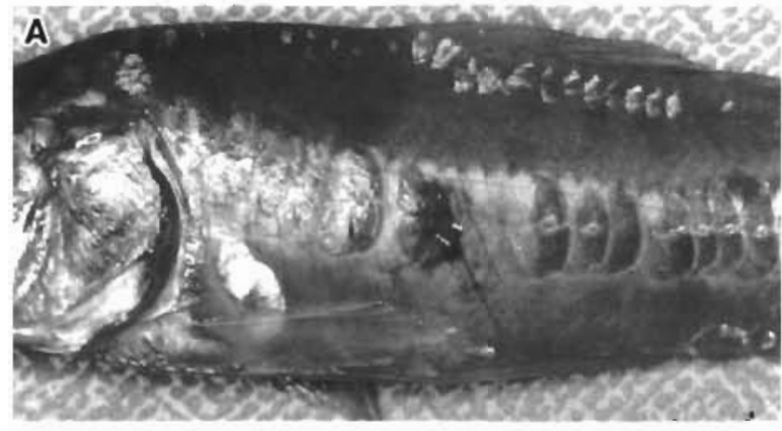

B
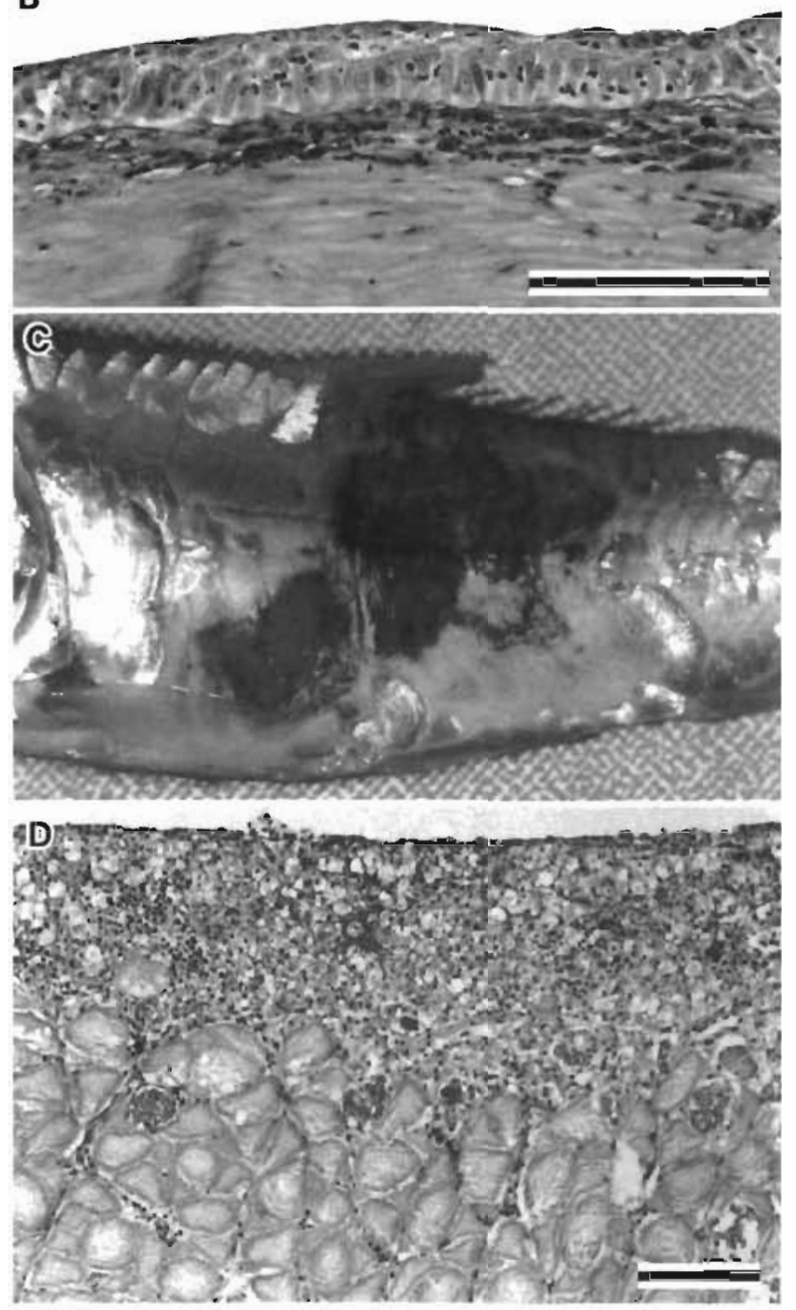

Fig. 5. Cyprinus carpio. (A) External view of a mirror carp that was intracutaneously inoculated with the cultured virus and placed in a drug bath. The fish shows a small lesion at the site of the injection. (B) Dermal lesion of fish shown in (A). The dermal loose connective tissue shows necrosis, hemorrhage and fibrin deposition. H\&E. Scale bar $=100 \mu \mathrm{m}$. (C) Mirror carp with an intracutaneous inoculation and no treatment with a drug bath. Fish shows extensive dermal lesions due to the invasion of water-borne bacteria. (D) Ulcerative lesion of fish shown in $(\mathrm{C})$. In the lesion, the skin has been destroyed. The underlying musculature shows necrosis of the muscle fibers, hemorrhage, fibrin deposition and infiltration of inflammatory cells. H\&E. Scale bar $=100 \mu \mathrm{m}$

\section{Infectivity experiments}

In the group that was treated with an intracutaneous inoculation and oxytetracycline treatment, the fish mostly displayed dermal lesions not only in the injected area but also at sites within the body on Days 5 to 7 (Fig. 5A). The lesions were usually erosive accompanied by intradermal hemorrhage and capillary dilation, and never became deeply ulcerated by the end of experiment. In the histological examinations of 5 fish which had been removed from the aquaria, dermal lesions usually exhibited necrosis of the dermal loose connective tissue accompanied by hemorrhage, fibrin deposition and inflammatory cellular infiltration (Fig. 5B). The overlying epidermis was thin and partially destroyed. Two of the 5 remaining fish died $(40 \%$ mortality). In the group that did not receive the oxytetracycline treatment, fish had dermal lesions displaying erosion or ulceration with intracutaneous hemorrhage not only at the injected site but also throughout the body (Fig. 5C). These lesions first appeared on Days 5 to 7 and then developed extensively. In the histological examinations of 3 fish which had been removed from the aquaria, the dermal lesions were erosive and ulcerative and had bacterial invasions (Fig. 5D). These lesions resembled those observed in natural outbreaks. In this group, 2 of the 5 remaining fish also died ( $40 \%$ mortality). In these 2 groups, the putative virus was re-isolated at $10^{3.8-5.5}$ TCID $_{50} \mathrm{~g}^{-1}$

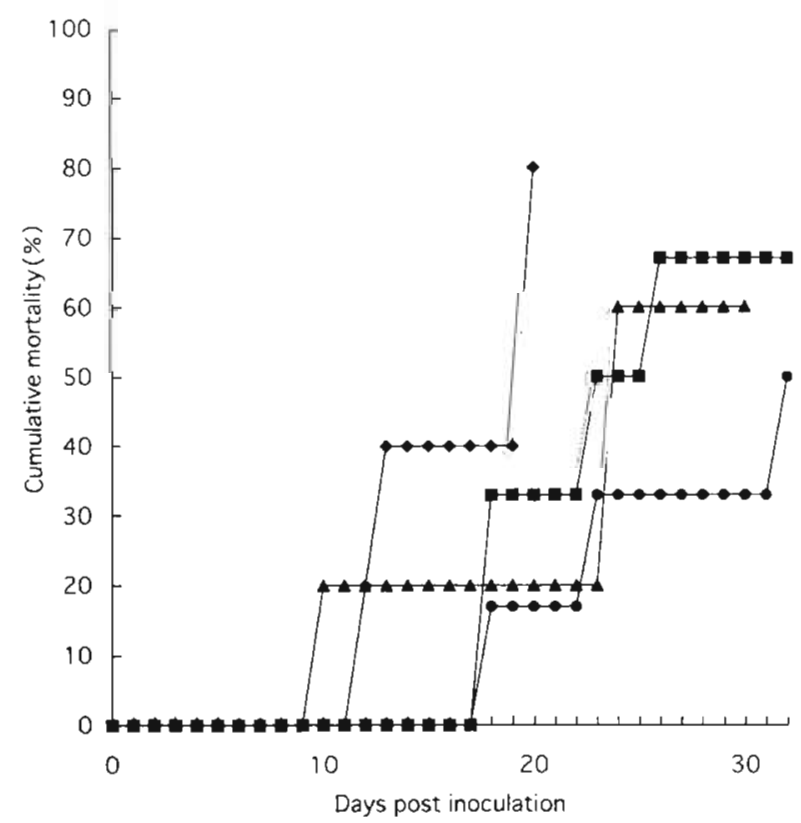

Fig. 6. Mortality graph of carps that were intraperitoneally inoculated with the virus. Because control groups had no dead fish, the graph is omitted. Inoculation doses: $(\bullet) 10^{5.0} \mathrm{TCID}_{50}$ $\mathrm{ml}^{-1}$ to $8 \mathrm{fish}$; $10^{5.4} \mathrm{TClD}_{50} \mathrm{ml}^{-1}$ to $6 \mathrm{fish}$; $10^{7.0} \mathrm{TCID}_{50}$ $\mathrm{ml}^{-1}$ to $5 \mathrm{fish} ;(\mathbf{\Delta}) 10^{7.0} \mathrm{TCID}_{50} \mathrm{ml}^{-1}$ to $5 \mathrm{fish}$ 


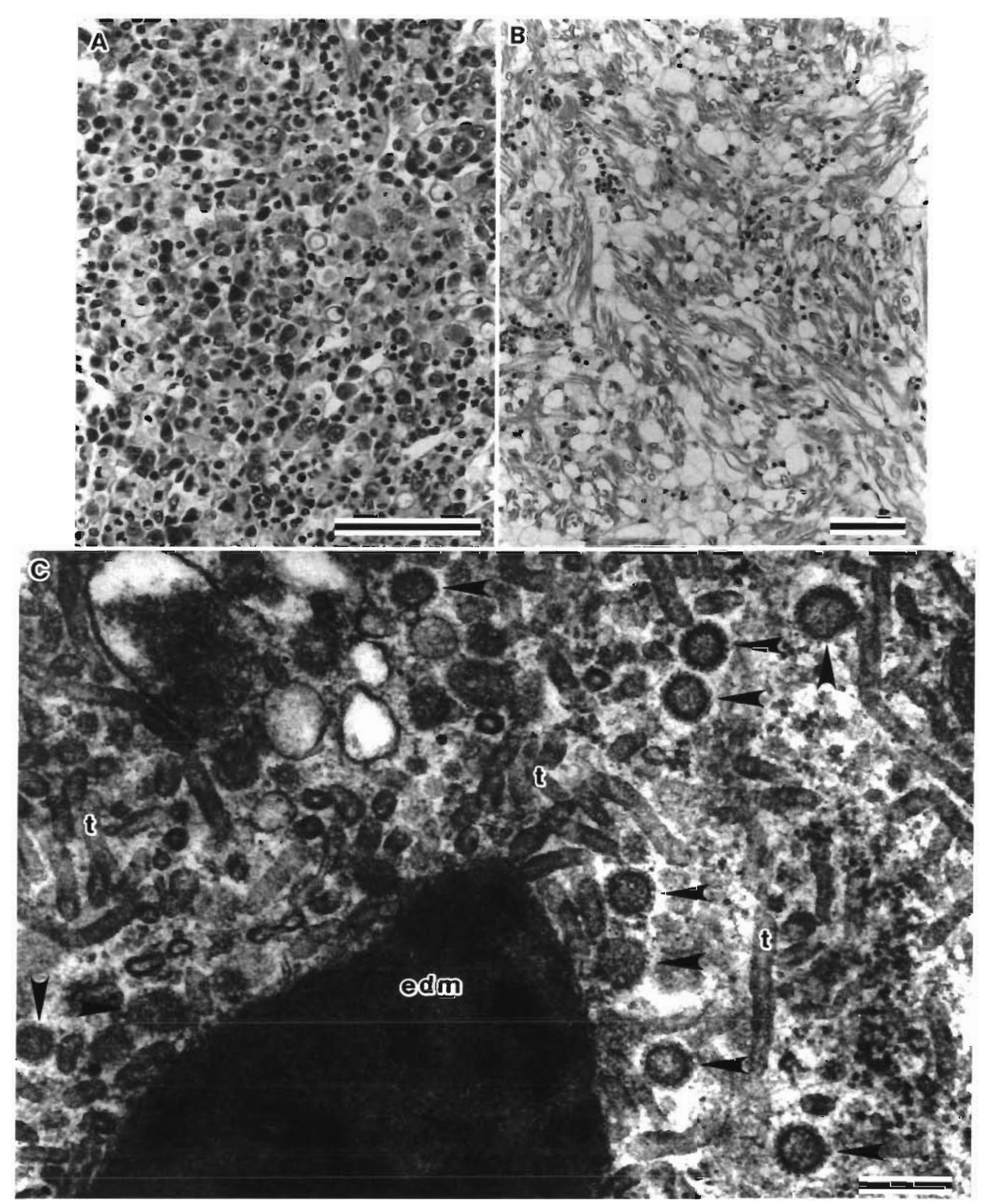

Fig. 7. $(A, B)$ Pathological changes in diseased fish infected by means of intraperitoneal inoculation with the cultured virus. H\&E. Scale bars $=50 \mu \mathrm{m}$. (A) Hematopoietic tissue displays many necrotized cells. (B) In the ventricle, cardiac muscle fibers extensively show vacuolar degeneration and necrosis. (C) An electron micrograph of an infected cell in the hematopoietic tissue. Virions (arrowheads), tubular structures (t) and electron-dense materials (edm) containing the initial stage of crystals appear in the cytoplasm. Scale bar $=200 \mathrm{~nm}$ 
from dermal lesions, $10^{4.5-6.0}$ TCID $_{50} \mathrm{~g}^{-1}$ from the kidney, and $10^{5.0-51}$ TCID $_{50} \mathrm{~g}^{-1}$ from the heart, which were obtained from dead or moribund fish. The surviving fish had healing dermal lesions. No virus was isolated from the kidney of the surviving fish or from the control fish. Moreover, in the 4 groups that were given intraperitoneal viral inoculations, none of the fish displayed any dermal lesions and 50 to $80 \%$ of the fish died during the experiments (Fig. 6). In moribund fish, the virus was frequently re-isolated at 104.7-7.5 TCID $_{50} \mathrm{~g}^{-1}$ from the kidney and $10^{3.9-4.4}$ TCID $_{50} \mathrm{~g}^{-1}$ from the heart. Virus was re-isolated from the kidney of the few fish that survived but not from any of the control fish.

Moribund fish in all experimental groups had infected lesions in the hematopoietic tissue (Fig. 7A), heart (Fig. 7B), spleen and the intestine. These pathological signs mostly resembled those that were found in natural outbreaks. In EM, infected cells in hematopoietic tissue (Fig. 7C), splenic pulps and cardiac muscle fibers displayed the same virions that were found in the natural outbreaks. Moreover, tubular structures and amorphous, electron-dense materials containing crystalline inclusions were also observed in necrotized cells in the hematopoietic tissue and spleen.

\section{DISCUSSION}

Carp are known to be affected by 3 viral diseases: spring viremia of carp caused by Rhabdovirus carpio (Fijan 1972), epidermal hyperplasia caused by Herpesvirus cyprini (Sano et al. 1985) and a pox-like virus (Oyamatsu et al. 1997). In the present study, the causative virus was different from the above 3 viruses. The virus was an RNA virus with an envelope possessing obvious spikes on the surface, and virus particles were present in the vacuolized cytoplasm of infected cells in the hematopoietic tissue and spleen, dermal fibrocytes and cardiac muscle fibers. The features of the putative virus resembled those of a coronavirus (Hosaka \& Matsumoto 1983). Some kinds of round particles with a spiked surface are known to be present as derivants of the Golgi apparatus, transporting vesicles formed by rough endoplasmic reticula and some kinds of acanthosomes in the cytoplasm of various cells of mammals (Fujita \& Fujita 1989). As mentioned in the 'Results' of this study, the putative viral particles did not resemble these round structures with spiked surfaces. Virally infected cells showed destroyed Golgi apparatus and endoplasmic reticula; therefore, in the infected cells the formation of derivants of the Golgi apparatus and transporting vesicles must be disturbed even if these target cells may form them in a normal situation. We are presently conducting studies on the genetic analysis of the causative virus for viral taxonomy.

In the hematopoietic tissue and spleen, infected cells characteristically displayed the formation of tubular structures and crystalline inclusions. Tubular structures resemble agranular endoplasmic reticula of adrenal cortex cells of humans (Fujita \& Fujita 1989), while there has been no report of the cells of fish. Because virally infected cells are not cells of the adrenal cortex, tubular structures are not agranular endoplasmic reticula. The tubular structures known to occur in virus infections of fishes appeared in cells that were infected with a birnavirus of infectious pancreatic necrosis (IPN: Kudo et al 1973). These tubular structures appeared to be formed accompanied by virus replication in this disease as well as in IPN. Crystalline inclusions have sometimes been observed in various cells of mammals but the association with virus infections has not been reported (Ghadially 1982). In this study, the crystalline inclusions were first revealed to be associated with a virus infection. We are presently conducting studies on the relationship between virus replication and formation of crystalline inclusions as well as tubular structures.

Carp that had been experimentally inoculated with the cultured virus showed virus transmission, the pathological signs of the disease and mortality. In the natural outbreak and infectivity experiments, a putative virus was isolated from the kidney, spleen and heart as well as from dermal lesions in which virusinfected cells were observed in EM. In some diseased fish, viral isolation resulted in a failure because the ulcerative lesion had been invaded by many bacteria. Such a systemic viral infection indicates that this disease is fundamentally a viremia. The diseased fish probably die from cardiac failure and disturbances of hemopoiesis. Dermal lesions appeared to be initiated when the virus invaded the skin, and developed into deep ulcers with secondary invasions of bacteria. In farming ponds and game-fishing ponds, diseased fish with ulcerative lesions usually occurred after rough handling of the fish. This phenomenon suggests that the causative virus initially invaded the slightly damaged epidermis to the dermis and then was disseminated into visceral organs, resulting in a viremia. In the natural outbreak, diseased fish showed mortalities even though they had only slight dermal lesions. In this case, diseased fish appear to die from the viremia as did the fish that were given an intraperitoneal inoculation in infectivity examinations. The authors propose that this new ana-aki-byo be called carp viremiaassociated ana-aki-byo (CVA).

Acknowledgements. This study was supported by a grant from the Japan Varicolored Carp Promotion Society. 


\section{LITERATURE CITED}

Bootsma R, Fijan N, Blonmaert J (1977) Isolation and preliminary identification of the causative agent of carp erythrodermatitis. Vet Arh 47:291-302

Eriot DG, Shotts EB (1980a) Aetiology of an uicerative disease in goldfish Carassius auratus (L.): microbiological examination of diseased fish from seven locations. J Fish Dis 3 : $133-143$

Eriot DG, Shotts EB (1980b) Aetiology of an ulcerative disease in goldfish Carassius auratus (L.): experimental induction of the disease. $J$ Fish Dis 3:145-151

Fijan $N$ (1972) Infectious dropsy in carp-a disease complex. In: Mawdesley-Thomas LE (ed) Disease of fish. Academic Press, London, p 39-49

Fujita H, Fujita T (1989) Textbook of histology. Igaku-shoin, Tokyo

Ghadially NF (1982) Ultrastructural pathology of the cell and matrix. Butterworths, London

Hosaka Y, Matsumoto A (1983) Atlas of virology. Electron microscopy. Asakura-shoten, Tokyo

Kudo S, Kurosawa D, Kunimine I, Nobusawa K, Kobayashi S (1973) Electron microscopic observations of the pancreas and liver in the fingerling rainbow trout with symptoms of IPN. Jpn J Ichthyol 20:163-177

Miyazaki T, Egusa S (1973) Ulcer disease of goldfish and crucian carp and Epistylis disease of color carp. Fish Pathol $7: 115-124$

Miyazaki T, Kubota SS, Egusa S (1976a) Studies on cold-

Editorial responsibility: Jo-Ann Leong,

Corvallis, Oregon, USA water ulcer disease in carp. I. Ulcerative lesion. Bull Fac Fish Mie Univ 3:49-58

Miyazaki T, Kubota SS, Egusa S (1976b) Studies on coldwater ulcer disease in carp. II. Healing lesion. Bull Fac Fish Mie Univ 3:59-66

Miyazaki T, Kubota SS, Egusa S (1976c) Studies on coldwater ulcer disease in carp. III. Visceral organs. Bull Fac Fish Mie Univ 3:67-73

Oyamatsu T, Hata N, Yamada K, Sano T, Fukuda H (1997) An etiological study on mass mortality of cultured colorcarp juvenile showing edema. Fish Pathol 32:81-88

Saito M, Nakamura T, Takahashi K (1975) Studies on ulcer disease of goldfish. II. Progression and healing of ulcer. Fish Pathol 9:179-186

Sano T, Fukuda H, Furukawa M (1985) Herpesvirus cyprini: biological and oncogenic properties. Fish Pathol 20: 381-388

Takahashi K, Kawana T, Nakamura T (1975a) Studies on ulcer disease of goldfish. I. Site of occurrence of ulcer. Fish Pathol 9:174-178

Takahashi K, Kawana T, Nakamura T (1975b) Studies on ulcer disease of goldfish. III. Infection experiment. Fish Pathol 9:187-192

Takahashi K, Kawana T, Nakamura T (1975c) Studies on ulcer disease of goldfish. IV. Bacteria isolated from lesions of diseased fish. Fish Pathol 10:22-30

Tomasec J, Fijan N (1971) Virusne bolestiriba (viral diseases of fish). Final report on research under a part of project 6n/1966, Zagreb

Submitted: July 15, 1999; Accepted: November 3, 1999 Proofs received from author(s): January 31, 2000 